\title{
To treat or not to treat: comparison of different criteria used to determine whether weight loss is to be recommended
} Ottavia Colombo*1, Simona Villani ${ }^{1}$, Giovanna Pinelli ${ }^{1}$, Claudia Trentani ${ }^{1}$, Maurizia Baldi ${ }^{2}$, Orazio Tomarchio ${ }^{2}$ and Anna Tagliabue ${ }^{1}$

Address: ${ }^{1}$ Department of Applied Health Sciences - University of Pavia, via A. Bassi 21, I-27100 Pavia, Italy and ${ }^{2}$ IRCCS Salvatore Maugeri Foundation, via Maugeri, I-27100 Pavia, Italy

Email: Ottavia Colombo* - ottavia.colombo@unipv.it; Simona Villani - simona.villani@unipv.it; Giovanna Pinelli - giovanna.pinelli@unipv.it; Claudia Trentani - claudia.trentani@unipv.it; Maurizia Baldi - mbaldi@fsm.it; Orazio Tomarchio - otomarchio@fsm.it;

Anna Tagliabue - anna.tagliabue@unipv.it

* Corresponding author

Published: 29 January 2008

Nutrition Journal 2008, 7:5 doi:10.1/86/1475-2891-7-5
Received: 27 February 2007

Accepted: 29 January 2008

This article is available from: http://www.nutritionj.com/content/7///5

(c) 2008 Colombo et al; licensee BioMed Central Ltd.

This is an Open Access article distributed under the terms of the Creative Commons Attribution License (http://creativecommons.org/licenses/by/2.0), which permits unrestricted use, distribution, and reproduction in any medium, provided the original work is properly cited.

\begin{abstract}
Background: Excess body fat is a major risk factor for disease primarily due to its endocrine activity. In recent years several criteria have been introduced to evaluate this factor. Nevertheless, treatment need is currently assessed only on the basis of an individual's Body Mass Index (BMI), calculated as body weight (in $\mathrm{kg}$ ) divided by height in $\mathrm{m}^{2}$. The aim of our study was to determine whether application of the BMI, compared to adiposity-based criteria, results in underestimation of the number of subjects needing lifestyle intervention.
\end{abstract}

Methods: We compared treatment need based on BMI classification with four adiposity-based criteria: percentage body fat (\%BF), considered both alone and in relation to metabolic syndrome risk (MS), waist circumference (WC), as an index of abdominal fat, and Body Fat Mass Index (BFMI, calculated as fat mass in $\mathrm{kg}$ divided by height in $\mathrm{m}^{2}$ ) in 63 volunteers ( 23 men and 40 women, aged $20-65$ years).

Results: According to the classification based on BMI, $6.3 \%$ of subjects were underweight, $52.4 \%$ were normal weight, $30.2 \%$ were overweight, and II.I\% were obese. Agreement between the BMI categories and the other classification criteria categories varied; the most notable discrepancy emerged in the underweight and overweight categories. BMI compared to almost all of the other adiposity-based criteria, identified a lower percentage of subjects for whom treatment would be recommended. In particular, the proportion of subjects for whom clinicians would strongly recommend weight loss on the basis of their BMI (II.I\%) was significantly lower than those identified according to WC (25.4\%, $p=0.004)$, \%BF $(28.6 \%, p=0.003)$, and MS $(33.9 \%, p=0.002)$.

Conclusion: The use of the BMI alone, as opposed to an assessment based on body composition, to identify individuals needing lifestyle intervention may lead to unfortunate misclassifications. Population-specific data on the relationships between body composition, morbidity, and mortality are needed to improve the diagnosis and treatment of at-risk individuals. 


\section{Background}

It is generally accepted that several major diseases are related to overweight and obesity. These include metabolic syndrome and type 2 diabetes mellitus, cardiovascular diseases, some tumours, gallbladder diseases, nonalcoholic steatohepatitis, sleep apnoea and osteoarthritis [1-6]. The endocrine activity of adipose tissue is strongly implicated in most of these diseases $[7,8]$. Therefore, excess body fat rather than excess body weight is detrimental to health; hence, paradoxically, metabolically obese, normal weight individuals, not deemed obese on the basis of height and weight parameters, were found to be hyperinsulinaemic, insulin-resistant, predisposed to type 2 diabetes mellitus, hypertriglyceridaemic, or to have premature coronary heart disease; these individuals responded favourably to caloric restriction [9-11].

Health professionals should assess patients on the basis of their body composition rather than their body weight [12]. Thus, new clinical criteria have been introduced to evaluate body adiposity, such as percentage body fat (\%BF), considered both alone [13] and in relation to metabolic syndrome risk [14], and waist circumference, as an index of abdominal fat $[1,15]$. Recently, the Body Fat Mass Index (BFMI, calculated as fat mass in kg divided by height in $\mathrm{m}^{2}$ ) was introduced, in nutritional assessment, as an additional element for assessing adiposity [16-18].

Nevertheless, treatment need is currently assessed on the basis of an individual's Body Mass Index (BMI), calculated as their body weight (in $\mathrm{kg}$ ) divided by their height in $\mathrm{m}^{2}$ [1].

The aim of our study was to determine whether application of the BMI, compared to adiposity-based criteria, results in underestimation of the number of subjects needing a lifestyle intervention.

\section{Methods \\ Sample}

A sample of 63 volunteers (all white, 23 men and 40 women, aged 20-65 years), was recruited. To be included in the study they had to have a good health status, a sedentary lifestyle, and could not be on a low-calorie diet or on drug therapy for acute or chronic illnesses. All the recruited subjects attended the Human Nutrition and Eating Disorders Research Centre, University of Pavia, between January 2004 and January 2005 to undergo a nutritional assessment and body composition analysis; the diagnostic radiology examinations were carried out at the IRCCS Salvatore Maugeri Foundation, Pavia.

\section{Study design}

The subjects attended the dietology outpatient clinic early in the morning after an overnight fast. On arrival, they emptied their bladders. Anthropometric measurements were taken. Body composition was assessed by means of bioimpedance analysis (BIA) and then dual-energy X-ray absorptiometry (DXA). Later in the morning, when the examinations were complete, the subjects were allowed to eat.

\section{Anthropometric measurements}

The subjects, wearing minimal clothing, were weighed to the nearest $0.1 \mathrm{~kg}$ using a balance beam scale equipped with a stadiometer. Their height, standing barefoot, was measured to the nearest $0.5 \mathrm{~cm}$. Their BMI was calculated in the standard way: weight in $\mathrm{kg}$ divided by height in $\mathrm{m}^{2}$. The subjects were then classified into four groups according to the WHO BMI cut-offs [1] :

$$
\begin{aligned}
& \text { A) BMI: "underweight" : BMI }<18.5 \mathrm{~kg} / \mathrm{m}^{2} \\
& \text { "normal weight": BMI }=18.5-24.9 \mathrm{~kg} / \mathrm{m}^{2} \\
& \text { "overweight" : BMI }=25-29.9 \mathrm{~kg} / \mathrm{m}^{2} \\
& \text { "obese" : BMI } \geq 30 \mathrm{~kg} / \mathrm{m}^{2}
\end{aligned}
$$

Waist circumference was measured to the nearest $0.1 \mathrm{~cm}$ with a measuring tape placed at the midpoint between the lower border of the ribs and the upper border of the pelvis. The subjects were then divided, according to genderspecific waist circumference values, into three categories denoting risk of metabolic complications [1] :

B) waist circumference as an index of abdominal fat:

"not increased" : $<80 \mathrm{~cm}$ females, $<94 \mathrm{~cm}$ males

"increased" : 80-87.9 cm females, 94-101.9 cm males

"substantially increased" : $\geq 88 \mathrm{~cm}$ females, $\geq 102 \mathrm{~cm}$ males

\section{Body composition assessment}

To reduce methodological biases when classifying subjects according to adiposity-based criteria, we used the same methods reported by the appropriate reference studies: DXA to measure \%BF (C) [13] ; and BIA to assess both metabolic syndrome risk (D) [14] and BFMI (E) [16].

DXA was performed using a Norland RX-26 scanner (Norland Corp., W, USA), which automatically gave a \%BF reading. BIA was performed using a Human Im Scan device (Dietosystem, Milan, Italy); \%BF was calculated using Deurenberg's formula [19]. The subjects were then classified according to different criteria: 
C) \%BF: the subjects were classified according to \%BF cutoffs calculated by Gallagher et al. for the white subgroup of their study population [13] (Table 1).

D) Metabolic syndrome risk: the subjects were classified on the basis of \%BF cut-offs calculated by Zhu in the white subgroup of the American population that took part in NHANES III [14] (Table 2).

E) Body Fat Mass Index: the subjects were classified according to the BFMI cut-offs calculated by Kyle on the basis of a very large sample of white men and women living in Switzerland [16] (Table 3).

To classify the subjects for whom weight loss would be recommended or strongly recommended (for each criterion), we applied the following cut-offs (also see Tables 1 , $2,3)$.

Weight loss recommended:

(A) $\mathrm{BMI} \geq 25 \mathrm{~kg} / \mathrm{m}^{2}$, in both women and men;

(B) waist circumference $\geq 80 \mathrm{~cm}$ in women and $\geq 94 \mathrm{~cm}$ in men;

(C) total body fat, expressed as percentage body fat: \%BF $\geq 33 \%$ in women and $\geq 21 \%$ in men in the $20-39$ years age group, $\% \mathrm{BF} \geq 35 \%$ in women and $\geq 23 \%$ in men aged $40-59$ years, $\% \mathrm{BF} \geq 38 \%$ in women and $\geq 25 \%$ in men aged 60-79 years;

(D) metabolic syndrome risk: $\% \mathrm{BF} \geq 30.8 \%$ in women and $\geq 21.2 \%$ in men;

Table I: Percentage body fat cut-offs for white people, proposed by Gallagher et al. [13].

\begin{tabular}{|c|c|c|}
\hline \multirow[t]{2}{*}{ BMI $\left(\mathrm{kg} / \mathrm{m}^{2}\right)$} & \multicolumn{2}{|c|}{ body fat (\% weight) } \\
\hline & Men & Women \\
\hline \multicolumn{3}{|l|}{$20-39 y$} \\
\hline 18.5 & 8 & 21 \\
\hline 25.0 & 21 & 33 \\
\hline 30.0 & 26 & 39 \\
\hline \multicolumn{3}{|l|}{$40-59$ y } \\
\hline 18.5 & 11 & 23 \\
\hline 25.0 & 23 & 35 \\
\hline 30.0 & 29 & $4 I$ \\
\hline \multicolumn{3}{|l|}{$60-79 y$} \\
\hline 18.5 & 13 & 25 \\
\hline 25.0 & 25 & 38 \\
\hline 30.0 & 31 & 43 \\
\hline
\end{tabular}

Table 2: Percentage body fat thresholds related to metabolic syndrome risk proposed by Zhu et al. for white people [14].

\begin{tabular}{ccc}
\hline BMI $\left(\mathbf{k g} / \mathbf{m}^{\mathbf{2}}\right)$ & \multicolumn{2}{c}{ body fat (\% weight) } \\
\cline { 2 - 3 } & Men & Women \\
\hline 18.5 & 11.0 & 22.5 \\
25.0 & 21.2 & 30.8 \\
30.0 & 29.1 & 37.2 \\
\hline
\end{tabular}

(E) BFMI $\geq 8.2 \mathrm{~kg} / \mathrm{m}^{2}$ in women and $\geq 5.2 \mathrm{~kg} / \mathrm{m}^{2}$ in men ("overfat").

Weight loss strongly recommended:

(A) $\mathrm{BMI} \geq 30 \mathrm{~kg} / \mathrm{m}^{2}$ in women and men;

(B) waist circumference $\geq 88 \mathrm{~cm}$ in women and $\geq 102 \mathrm{~cm}$ in men;

(C) total body fat, expressed as percentage body fat: \%BF $\geq 39 \%$ in women and $\geq 26 \%$ in men in the $20-39$ years age group, $\% \mathrm{BF} \geq 41 \%$ in women and $\geq 29 \%$ in men aged $40-59$ years, $\% B F \geq 43 \%$ in women and $\geq 31 \%$ in men aged $60-79$ years;

(D) metabolic syndrome risk: $\% \mathrm{BF} \geq 37.2 \%$ in women and $\geq 29.1 \%$ in men;

(E) BFMI $\geq 11.8 \mathrm{~kg} / \mathrm{m}^{2}$ in women and $\geq 8.3 \mathrm{~kg} / \mathrm{m}^{2}$ in men (severely "overfat").

\section{Statistical analysis}

Sex-related differences in anthropometric measurements and body fat indices were tested using unpaired t-tests or $\chi^{2}$-tests. Statistical significance was defined as $\mathrm{p}<0.05$. Agreement between BMI and abdominal fat, \%BF, metabolic syndrome risk, and BFMI was evaluated using Kendall's Tau-b test. McNemar's test was applied to evaluate whether the percentage of subjects in whom weight loss was deemed necessary on the basis of BMI was equal to the percentages identified on the basis of the other body composition assessments; similarly, the percentage of

Table 3: Body Fat Mass Index (BFMI) cut-offs for healthy white adults, proposed by Kyle et al. [16].

\begin{tabular}{ccc}
\hline BMI $\left(\mathbf{k g} / \mathbf{m}^{2}\right)$ & \multicolumn{2}{c}{ BFMI $\left(\mathbf{k g} / \mathbf{m}^{2}\right)$} \\
\cline { 2 - 3 } & Men & Women \\
\hline 18.5 & 1.8 & 3.9 \\
25.0 & 5.2 & 8.2 \\
30.0 & 8.3 & 11.8 \\
\hline
\end{tabular}


subjects whose BMI would prompt a strong recommendation to lose weight was compared to the percentages of subjects in whom application of each of the other adiposity classification criteria also revealed a definite need to lose weight. All analyses were carried out with the statistical software program SPSS, version 13.0.

\section{Statement of ethics}

We certify that this research complied fully with all applicable institutional and governmental regulations concerning the ethical use of human volunteers and with the terms of the Helsinki Declaration. The University of Pavia ethics committee approved the study protocol, and all the recruited subjects gave their written informed consent to take part.

\section{Results}

The women enrolled in the study were slightly younger than the men $(38.5 \pm 14$ years vs $39.2 \pm 13.3$ years), but this difference was not statistically significant $(t=0.201$, $\mathrm{p}$ $=0.841)$.

On average, the men recorded higher body weight, waist circumference and BFMI values than the women, while the women had a higher \% $\mathrm{BF}$ and metabolic syndrome risk (Table 4). Body fat percentage measured by DXA was significantly linearly related to that measured by BIA $\left(r_{\text {Pear- }}\right.$ $\mathrm{son}=0.827, \mathrm{p}<0.0001)$.

According to the classification based on BMI, $6.3 \%$ of subjects were underweight, $52.4 \%$ were normal weight, $30.2 \%$ were overweight, and $11.1 \%$ were obese. Abdominal adiposity was not increased in $63.5 \%$ of subjects, increased in $11.1 \%$, and substantially increased in $25.4 \%$. Total body fat, considered alone, was low in $3.2 \%$ of subjects, normal in $49.2 \%$, increased in $19.0 \%$, and high in $28.6 \%$. Metabolic syndrome risk related to $\% \mathrm{BF}$ was low in $7.1 \%$ of subjects, normal in $37.5 \%$, increased in $21.4 \%$, and high in $33.9 \%$. BFMI was low in $3.6 \%$ of subjects, normal in $42.9 \%$, increased in $32.1 \%$, and high in $21.4 \%$.

Metabolic syndrome risk was the only criterion to show significant gender-related differences $\left(\chi^{2}=9.430 ; \mathrm{p}=\right.$ $0.024)$ : greater percentages of the women compared to the men showed a high metabolic syndrome risk $(37.1 \%$ vs
$28.6 \%)$, and a low and normal metabolic syndrome risk ( $8.6 \%$ vs $4.8 \%$ and $45.7 \%$ vs $23.8 \%$, respectively); conversely, a greater proportion of the men had an increased metabolic syndrome risk ( $42.9 \%$ vs $8.6 \%$ ).

Agreement between the BMI categories and the other classification criteria categories varied (Table 5). The most notable discrepancy emerged in the underweight and overweight categories. Of the subjects classed as underweight on the basis of BMI, 75\% had normal \%BF and metabolic syndrome risk values, and none had an increased waist circumference. In the BMI normal weight subjects, increased abdominal fat was found in $9.1 \%$, increased \%BF in $15.2 \%$, and increased metabolic syndrome risk in 20\%; a high \%BF was found in $6.1 \%$ of the normal weight subjects and a high metabolic syndrome risk in $16.7 \%$. In the overweight subjects, a marked discrepancy emerged between the BMI and the adiposity indices: more than $50 \%$ of the subjects had a high \%BF and metabolic syndrome risk and just under 50\% high abdominal fat. In the subjects rated as obese on the basis of their BMI, there was good agreement between all the criteria.

Comparing the BMI with the BFMI categories, $75 \%$ of the underweight subjects had a normal fat status. In the BMI normal weight category, $30 \%$ of the subjects were "overfat" according to the BFMI, while in the overweight category only $6.7 \%$ of subjects had a normal fat status and $40 \%$ had a severely "overfat" status. There was good agreement between BMI and BFMI in the obese subjects. Overall, the BMI showed good agreement with BFMI (tau-b Kendall $=0.722, \mathrm{p}<0.001)$ and waist circumference (abdominal fat) (tau-b Kendall $=0.704, \mathrm{p}<0.001)$. The level of agreement between the various BMI categories and the \%BF and metabolic syndrome risk categories was moderate (tau-b Kendall $=0.672, \mathrm{p}<0.001$ and tau-b Kendall $=0.563, \mathrm{p}<0.001$ respectively $)$.

The percentages of subjects for whom weight loss treatment would be recommended and strongly recommended, on the basis of each criterion, are summarised in figure 1 . The proportion of subjects for whom clinicians would recommend weight loss on the basis of their BMI $(41.3 \%)$ was not significantly different from the propor-

Table 4: Summary of statistics by sex (mean values and standard deviations in square brackets).

\begin{tabular}{|c|c|c|c|c|c|c|c|}
\hline & $\mathbf{n}$ & Weight (kg) & BMI $\left(\mathrm{kg} / \mathrm{m}^{2}\right)$ & \%BF & MS & WC (cm) & BFMI $\left(\mathrm{kg} / \mathrm{m}^{2}\right)$ \\
\hline Men & 23 & $75.3[11.2]$ & 24.7 [3.9] & $21.5[8.6]$ & $24.2[7.6]$ & $89.5[10.8]$ & $6.2[2.8]$ \\
\hline Women & 40 & $62.0[11.0]$ & $23.8[4.2]$ & $34.8[8.4]$ & $32.6[9.1]$ & $80.8[12.2]$ & $8.0[3.3]$ \\
\hline Test and p-value & & $\begin{array}{c}t=4.59 \\
p<0.0001\end{array}$ & $\begin{aligned} t & =0.78 \\
p & =0.438\end{aligned}$ & $\begin{array}{c}t=-6.00 \\
p<0.0001\end{array}$ & $\begin{array}{l}t=-3.52 \\
P<0.001\end{array}$ & $\begin{array}{l}t=2.83 \\
p=0.006\end{array}$ & $\begin{array}{l}t=-2.01 \\
p=0.049\end{array}$ \\
\hline
\end{tabular}

$\% B F=$ total body fat, expressed as percentage body fat; $M S=$ metabolic syndrome risk: \%BF related to the risk of developing metabolic syndrome; $W C=$ waist circumference, as an index of abdominal fat; BFMI = Body Fat Mass Index 
Table 5: Agreement between the BMI categories and the other classification criteria categories expressed as percentage values. The values in bold represent the main diagonal of the agreement matrix.

\begin{tabular}{|c|c|c|c|c|}
\hline Other classification criteria categories & \multicolumn{4}{|c|}{ Body Mass Index } \\
\hline & underweight & normal weight & overweight & obese \\
\hline \multicolumn{5}{|l|}{ low } \\
\hline$\% B F$ & 25.0 & 3.0 & - & - \\
\hline MS & 25.0 & 10.0 & - & - \\
\hline BFMI & 25.0 & 3.3 & - & - \\
\hline \multicolumn{5}{|l|}{ normal } \\
\hline$\% B F$ & 75.0 & 75.8 & 15.8 & - \\
\hline MS & 75.0 & 53.3 & 6.7 & 14.3 \\
\hline WC & 100.0 & 90.9 & 31.6 & - \\
\hline BFMI & 75.0 & 66.7 & 6.7 & - \\
\hline \multicolumn{5}{|l|}{ increased } \\
\hline$\% B F$ & - & 15.2 & 31.6 & 14.3 \\
\hline MS & - & 20.0 & 40.0 & - \\
\hline WC & - & 9.1 & 21.1 & - \\
\hline BFMI & - & 30.0 & 53.3 & 14.3 \\
\hline \multicolumn{5}{|l|}{ high } \\
\hline$\% B F$ & - & 6.1 & 52.6 & 85.7 \\
\hline MS & - & 16.7 & 53.3 & 85.7 \\
\hline WC & - & - & 47.4 & 100.0 \\
\hline BFMI & - & - & 40.0 & 85.7 \\
\hline
\end{tabular}

$\% B F=$ total body fat, expressed as percentage body fat; $M S=$ metabolic syndrome risk: \%BF related to the risk of developing metabolic syndrome; $W C=$ waist circumference, as an index of abdominal fat; $B F M I=$ Body Fat Mass Index

tions in whom it would be recommended on the basis of $\% B F(p=0.344)$ and abdominal fat $(\mathrm{p}=0.508)$. Conversely, a significant difference emerged in relation to the criteria metabolic syndrome risk $(\mathrm{p}=0.022)$ and BFMI ( $=0.021)$. The picture changes when analysing the proportion of subjects for whom weight loss would be strongly recommended, with the proportion identified on the basis of BMI (11.1\%) differing significantly from the proportion identified by abdominal fat $(\mathrm{p}=0.004), \% \mathrm{BF}(\mathrm{p}$ $=0.003)$, and metabolic syndrome risk $(\mathrm{p}=0.002)$. Instead, no significant difference was found between the proportions of subjects whom clinicians, on the basis of BMI versus BFMI, would be strongly urged to lose weight $(\mathrm{p}=0.125)$.

\section{Discussion}

Obesity is a metabolic disorder characterised by excess body fat, which is an important risk factor for disease, not only because it is a volume-filling organ, but primarily due to the endocrine activity of adipose tissue $[7,8,20]$.

Although the BMI is easily calculated and can be readily used in population studies, it does not discriminate between fat mass and fat-free mass, or reflect the fat mass distribution in the body [21-25]. In our study, the BMI compared to almost all of the other criteria, based on adiposity, identified a lower percentage of subjects for whom treatment would be recommended and strongly recommended. In particular, the difference was statistically sig- nificant when the BMI was compared to metabolic syndrome risk. These findings suggest that a certain proportion of subjects classified as normal weight on the basis of their BMI would not be recommended for treatment even though they harbour excess body fat which could have clinical and metabolic consequences. This is also true if we compare the BMI to the BFMI, the latter an index that denotes the amount of body fat in relation to stature. Indeed, the BFMI, which can be considered a qualitative evaluation of BMI, can result in a better clinical assessment of subjects. From a clinical point of view, basing an individual's treatment needs on their BMI can place at risk those subjects who, on the basis of their metabolic syndrome risk, \%BF, and waist circumference, would be strongly advised to undergo weight-loss treatment.

As regards the underweight subjects, a large proportion of them had normal (not low) \%BF, waist circumference, metabolic syndrome risk, and BFMI values. However, in these subjects, the misclassification does not have important clinical consequences, since treatment would not, on the basis of any of the criteria, be recommended for any of them.

Thus, our data confirm that indirect estimates of body composition (i.e. BMI) are useful for groups but unreliable in individuals [26]. Furthermore, our data also underline the importance of discriminating between lean mass and fat mass, and of relating these parameters to body 


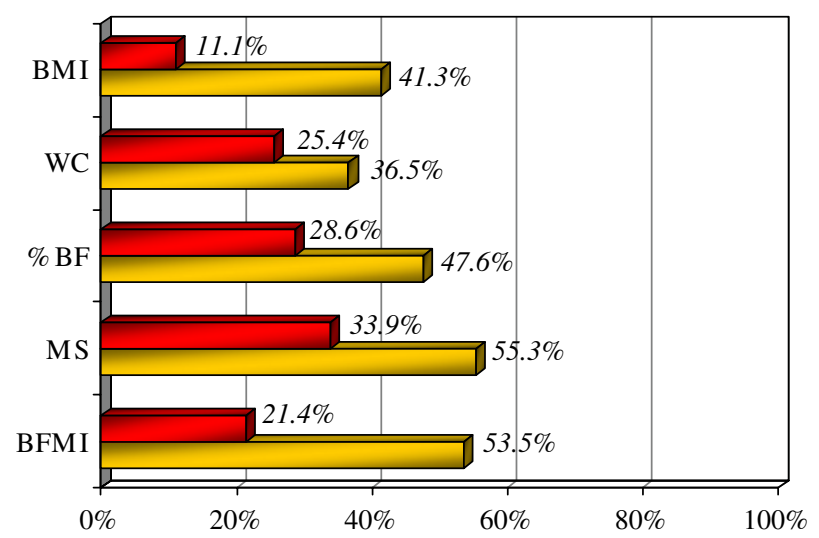

Weight loss recommended $\square$ Weight loss strongly recommended

Figure I

Weight loss treatment recommendations for each criterion. Percentage of subjects for whom weight loss would be recommended, including those for whom it would be strongly recommended, on the basis of the different criteria: BMI (Body Mass Index), WC (waist circumference, as an index of abdominal fat), \%BF (total body fat, expressed as percentage body fat), MS (metabolic syndrome risk: \%BF related to the risk of developing metabolic syndrome), BFMI (Body Fat Mass Index)

height, in order to obtain a better nutritional assessment. In addition, the clinical consequences of an altered body composition should be taken into account. The use of the BMI alone to evaluate overweight and obese individuals leads to undesirable misclassifications. Of note, our study sample consisted of people with a sedentary lifestyle, which may predispose them to increased adiposity even before an increase in body weight becomes evident; this implies that normal weight subjects can be at risk of excessive adiposity.

Thus, there is a need to replace the BMI or to supplement it with other diagnostic criteria, in particular, ones that focus on body adiposity, considered both alone and with regard to its distribution. If confirmed by data from larger studies, our results highlight the need to investigate the clinical consequences of excess body fat in normal weight subjects. Several studies have focused on the relationship between the BMI and morbidity and mortality $[2,3,27]$. Unfortunately, to date, few studies have focused on the relationship between \%BF and morbidity and mortality, and those that have been conducted were restricted to specific ethnic groups $[14,16,28-31]$. Thus, precise \%BF cutoffs that can be used in clinical settings to evaluate an individual's health remain to be determined.
Since \%BF has important clinical consequences, and treatment costs and drop-out rates among "overfat" subjects are high, there is clearly a pressing need for precise and unambiguous guidelines. In particular, \%BF cut-offs should be defined that can be used in addition to the BMI and waist circumference values already published for the diagnosis and treatment of at-risk subjects [1].

\section{Conclusion}

The use of the BMI alone, as opposed to an assessment based on body composition, to identify individuals needing lifestyle intervention may lead to unfortunate misclassifications. Population-specific data on the relationships between body composition, morbidity, and mortality are needed to improve the diagnosis and treatment of at-risk individuals.

\section{Competing interests}

The author(s) declare that they have no competing interests.

\section{Authors' contributions}

OC: conception and design of the study; generation, collection and assembly of data; interpretation of data; drafting of the manuscript. SV: analysis and interpretation of data. GP: conception and design of the study; generation, collection and assembly of data. CT: conception and design of the study. MT: collection, assembly and interpretation of data. OT: collection, assembly and interpretation of data. AT: conception and design of the study; generation, collection and assembly of data; interpretation of data; drafting of the manuscript. All the authors have read and approved the final manuscript.

\section{References}

I. World Health Organization: Obesity preventing and managing the global epidemic. In Report of a WHO consultation on Obesity. WHO Technical Report Series No. 894 WHO: Geneva; 1998.

2. Overweight, Obesity and Health Risk. National Task Force on the Prevention and Treatment of Obesity. Arch Intern Med 2000, 160(7):898-904. Review.

3. Willett W, Dietz WH, Colditz GA: Guidelines for healthy weight. N Engl J Med I999, 34 I(6):427-434.

4. Vigneri P, Frasca F, Sciacca L, Frittitta L, Vigneri R: Obesity and cancer. Nutr Metab Cardiovasc Dis 2006, I 6(1): I-7.

5. Jonsson S, Hedblad B, Engstrom G, Nilsson P, Berglund G, Janzon L: Influence of obesity and cardiovascular risk. Twenty-threeyear follow-up of 22,025 men from an urban Swedish population. Int J Obes Relat Metab Disord 2002, 26(8): I046-I053.

6. Fatati G: Dall'insulinoresistenza alla Sindrome metabolica Critical Medicine Publishing: Rome; 2004.

7. Trayhurn P: Endocrine and signalling role of adipose tissue: new perspective on fat. Acta Physiol Scand 2005, 184:285-293. Review.

8. Murdolo G, Smith U: The dysregulated adipose tissue : a connecting link between insulin resistance, type 2 diabetes mellitus and atherosclerosis. Nutr Metab Cardiovasc Dis 2006, 16(Suppl I):S35-S38.

9. Tanaka S, Togashi K, Rankinen T, Pérusse L, Leon AS, Rao DC, Skinner JS, Wilmore JH, Bouchard C: Is adiposity at normal body weight relevant for cardiovascular disease risk? Int J Obes Relat Metab Disord 2002, 26(2): 176-183. 
10. Ruderman NB, Schneider SH, Berchtold P: The "metabolicallyobese", normal-weight individual. Am J Clin Nutr 198I, 34(8): $1617-162 \mid$.

II. Ruderman N, Chisholm D, Pi-Sunyer X, Schneider S: The metabolically obese, normal-weight individual revisited. Diabetes 1998, 47(5):699-713. Review.

12. Flegal KM, Troiano RP, Ballard-Barbash R: Aim for a healthy weight: what is the target? J Nutr 200I, I3 I (2S-I):440S-450S.

13. Gallagher D, Heymsfield SB, Heo M, Jebb SA, Murgatroyd PR, Sakamoto $Y$ : Healthy percentage body fat ranges: an approach for developing guidelines based on body mass index. Am J Clin Nutr 2000, 72:694-701.

14. Zhu S, Wang ZM, Shen W, Heymsfield SB, Heshka S: Percentage body fat ranges associated with metabolic syndrome risk: results based on the third National Health and Nutrition Examination Survey (1988-1994). Am J Clin Nutr 2003, 78:228-235.

15. Després JP, Lemieux I, Prud'homme D: Treatment of obesity: need to focus on high risk abdominally obese patients. $B M J$ 200I, 322:716-720.

16. Kyle UG, Schutz Y, Dupertuis YM, Pichard C: Body composition interpretation: contributions of the Fat-Free Mass Index and the Body Fat Mass Index. Nutrition 2003, 19:597-604.

17. Vanltallie TB, Yang MU, Heymsfield SB, Funk RC, Boileau RA: Height-normalized indices of the body's fat-free mass and fat mass: potentially useful indicators of nutritional status. Am J Clin Nutr 1990, 52:953-959.

18. Schutz Y, Kyle UG, Pichard C: Fat-free mass index and fat mass index percentiles in Caucasian aged 18-98 y. Int J Obes Relat Metab Disord 2002, 26:953-960.

19. Deurenberg P, van der Kooy K, Leenen R, Weststrate JA, Seidell JC: Sex and age specific prediction formulas for estimating body composition from bioelectrical impedance: a cross-validation study. Int J Obes I99I, I 5(I):17-25.

20. Cinti S: The adipose organ Kurtis: Milan; 1999.

21. Frankenfield DC, Rowe WA, Cooney RN, Stanley Smith J, Becker D: Limits of Body Mass Index to detect obesity and predict body composition. Nutrition 200I, 17:26-30.

22. Kuczmarski RJ, Flegal KM: Criteria for definition of overweight in transition: background and recommendation for the United States. Am J Clin Nutr 2000, 72: I074-108I. Special Article.

23. Romero-Corral A, Montori VM, Somers VK, Korinek J, Thomas RJ, Allison TG, Mookadam F, Lopez-Jimenez F: Association of body weight with total mortality and with cardiovascular events in coronary artery disease: a systematic review of cohort studies. Lancet 2006, 368:666-678.

24. Morabia A, Ross A, Curtin F, Pichard C, Slosman DO: Relation of $B M I$ to a dual-energy $X$-ray absorptiometry measure of fatness. Br J Nutr 1999, 82:49-55.

25. He M, Tan KC, Li ET, Kung AW: Body fat determination by dualenergy $\mathrm{X}$-ray absorptiometry and its relation to body mass index and waist circumference in Hong Kong Chinese. Int Obes Relat Metab Disord 200I, 25:748-752.

26. Piers LS, Soares MJ, Frandsen SL, O'Dea K: Indirect estimates of body composition are useful for groups but unreliable for individuals. Int / Obes Relat Metab Disord 2000, 24: I |45- I I 52.

27. Troiano RP, Frongillo EA Jr, Sobal J, Levitsky DA: The relationship between body weight and mortality: a quantitative analysis of combined information from existing studies. Int J Obes Relat Metab Disord 1996, 20(I):63-75.

28. Ito H, Nakasuga K, Ohshima A, Maruyama T, Kaji Y, Harada M, Fukunaga $M$, Jingu $S$, Sakamoto $M$ : Detection of cardiovascular risk factors by indices of obesity obtained from anthropometry and dual-energy $\mathbf{X}$-ray absorptiometry in Japanese individuals. Int J Obes Relat Metab Disord 2003, 27:232-237.

29. Dobbelsteyn CJ, Joffres MR, MacLean DR, Flowerdew G: A comparative evaluation of waist circumference, waist-to-hip ratio and body mass index as indicators of cardiovascular risk factors. The Canadian Heart Health Surveys. Int J Obes Relat Metab Disord 200I, 25(5):652-66I.

30. Wu CH, Yao WJ, Lu FH, Wu JS, Chang CJ: Relationship between glycosylated haemoglobin, blood pressure, serum lipid profiles and body fat distribution in healthy Chinese. Atherosclerosis 1998, I37(I): 157-165.

31. Perichart-Perera $O$, Balas-Nakash M, Schiffman-Selechnick E, Barbato-Dosal A, Vadillo-Ortega $F$ : Obesity increases metabolic syndrome risk factors in school-aged children from an urban school in Mexico city. J Am Diet Assoc 2007, 107(I):8I-91.
Publish with Bio Med Central and every scientist can read your work free of charge

"BioMed Central will be the most significant development for disseminating the results of biomedical research in our lifetime. "

Sir Paul Nurse, Cancer Research UK

Your research papers will be:

- available free of charge to the entire biomedical community

- peer reviewed and published immediately upon acceptance

- cited in PubMed and archived on PubMed Central

- yours - you keep the copyright 